\title{
Soundscape and its Influence on Tourist Satisfaction
}

\author{
Aili LIU ${ }^{\mathrm{a}}$, Xuan Lorna WANG ${ }^{\mathrm{b} *}$, Fucheng LIU ${ }^{\mathrm{a}}$, Changhong YAO ${ }^{\mathrm{a}}$, Zhiyong DENG \\ ${ }^{a}$ College of Resource Environment and Tourism, Capital Normal University, Beijing, 100048, \\ China; \\ ${ }^{\mathrm{b}}$ School of Hospitality and Tourism Management, University of Surrey, Guildford, GU2 7XH, \\ $\mathrm{UK}$; \\ ${ }^{\mathrm{c}}$ College of Music, Capital Normal University, Beijing, 100048, China
}

\begin{abstract}
The soundscape is a relatively neglected area of study in tourism and to a wider extent the service industries research. This paper examines the relationship between soundscape and tourist satisfaction from a tourist sensory experience perspective. Data were collected in a popular cultural and heritage tourism destination in China, a UNESCO world heritage site and well known for its unique soundscape. The structural equation model analysis shows that there is a significant correlation between soundscape satisfaction and tourist satisfaction. The analysis of the findings also suggests that sound preference has almost no influence on soundscape satisfaction and tourist satisfaction, while soundscape expectation has a strong influence on tourist satisfaction. This study extends the service industries multi-sensory research by offering insights into the relationship between the soundscape perceptions and tourist satisfaction. The findings also reveal that soundscapes could enhance tourist satisfaction and possibly define the sense of a place.
\end{abstract}

Keywords: Soundscape; tourist satisfaction; tourist sensory experience; tourist sensory satisfaction; Chinese tourists

\section{Acknowledgment}

This research has been funded by National Natural Science Foundation of China (41401156) and Tourism Young Expert Training Program of China National Tourism Administration (TYETP201506).

*Corresponding author 


\title{
Soundscape and its Influence on Tourist Satisfaction
}

\begin{abstract}
The soundscape is a relatively neglected area of study in tourism and to a wider extent the service industries research. This paper examines the relationship between soundscape and tourist satisfaction from a tourist sensory experience perspective. Data were collected in a popular cultural and heritage tourism destination in China, a UNESCO world heritage site and well known for its unique soundscape. The structural equation model analysis shows that there is a significant correlation between soundscape satisfaction and tourist satisfaction. The analysis of the findings also suggests that sound preference has almost no influence on soundscape satisfaction and tourist satisfaction, while soundscape expectation has a strong influence on tourist satisfaction. This study extends the service industries multi-sensory research by offering insights into the relationship between the soundscape perceptions and tourist satisfaction. The findings also reveal that soundscapes could enhance tourist satisfaction and possibly define the sense of a place.
\end{abstract}

Keywords: Soundscape; tourist satisfaction; tourist sensory experience; tourist sensory satisfaction; Chinese tourists 


\section{INTRODUCTION}

The sensory dimension of tourist experiences has drawn increasing attention in recent years (Agapito, Mendes, \& Valle, 2013; Agapito, Valle, \& Mendes, 2014; Jensen, Scarles, \& Cohen, 2015). However, the visual dimension appears to have attracted more scholarly attention than the other four human senses: sound, smell, taste and touch (Pan \& Ryan, 2009; Rojek \& Urry, 1997) partially influenced by the well-embraced concept of 'tourist gaze' (Urry, 1990). Porteous (1990, p.7) questions the hegemony of visuality and stating that vision 'is a cool, detached sense, and sight alone is insufficient for a true involvement of self with the world'. This view is shared by leading tourism academics who also suggest that the tourist experiences 'are not merely visual but multisensory' (Pan \& Ryan, 2009, p. 625; Schwarz, 2013, p. 382) and tourism should involve various sensescapes, such as soundscapes, smellscapes, tastescapes, and the geography of touch in addition to landscapes (Urry, 2002, p. 146; Quan \& Wang, 2004, p. 303).

Sounds, as well as the soundscape of destinations are among the main focuses of tourists' sensory experiences. The importance of sound to tourists lies in at least two aspects. On the one hand, sound could be the core element of tourist attractions and it could be seen as one of the intangible resources that tourists consume when travelling (Briassoulis, 2002). For instance, niche tourism such as music tourism (Sellars, 1998). On the other hand, sound could help tourists to establish the sense of a place (Liu, Hu, Liu, Deng, \& Yao, 2013) and enhance tourists' perception and understanding of a destination such as nature (Merchan, DiazBalteiro, \& Solino, 2014). Thus, the call for putting 'the non-visual aspects of the tourist experience' on the research agenda (Quan and Wang, 2004, p. 303). However, studies on sound and tourist experiences remain to be limited and they mainly focus on three themes. First, noise pollution and its influence on tourists (Tarrant, Haas, \& Manfredo, 1995; Benfield, Bell, Troup, \& Soderstrom, 2005; Mace, Corser, Zitting, \& Denison, 2013; Morillas, Escobar, \& Gozalo, 2013; Merchan, Diaz-Balteiro \& Solino, 2014; Taff, Newman, Lawson, Bright, Martin, Gibson, \& Archie, 2014). Second, the value and importance of a natural quiet soundscape (Waltonen \& Veijola, 2011; Rantala \& Valtonen, 2014; Pheasant, Fisher, Watts, Whitaker, \& Horoshenkov, 2010; Watts \& Pheasant, 2015); and third, the multisensescape experience and sonic interpretation (Quan \& Wang, 2004; Waitt \& Duffy, 2010; Edensor, 2000; Richards, Pritchard, \& Morgan, 2010; Kang \& Gretzel, 2011; Wolf, Stricker, \& Hagenloh, 2013). It is unsurprising that Waitt and Duffy (2010, p.457) point out that tourism studies should pay closer attention to the ear and listening, because the 'tyranny of the visual' has marginalized the status of sound, smell, touch and the other senses (Saldanha, 2009).

The main conclusions that could be drawn from previous studies include that the acoustic environment (the soundscape) of the destination plays a key role in cultivating a positive visitor experience and satisfaction, and that natural quietness is vital for visitors to enjoy the expected landscape at the same time as manmade sound (noise to some people) should be strictly controlled. Although previous studies have confirmed that a noisy acoustic environment would affect tourists' experiences, and visitors would like to pay an entrance fee for the purpose of mitigating noise (Merchan, Diaz-Balteiro, \& Solino, 2014), little research has been done to examine the relationship between soundscape perception, especially soundscape satisfaction, and tourist satisfaction.

As an established area of research, tourist satisfaction has been studied comprehensively in many tourism sectors such as travel agencies, accommodation, destinations and tours 
(Bosque \& Martin, 2008). It refers to tourists' feeling of gratification when the post-travel experience exceeds prior expectations (Chen \& Chen, 2010); therefore, tourist satisfaction is perceived as an assessment tool to evaluate travel experiences (Lu, Chi, \& Liu, 2015). Perspectives and theories used to examine tourist satisfaction include the expectation and disconfirmation model (Oliver, 1987), equity theory (Swan \& Combs, 1976), the norm theory (LaTour and Peat, 1979) and the perceived performance model (Tse and Wilton, 1988). Variables used for measurement focus more on service quality, ease of use, efficiency, cost and so on (Neal \& Gursoy, 2008), rather than on environmental factors (Pizam, Neumann and Reichel, 1978) such as sound and the soundscape. More recently, Kirillova et al., (2014) reveal the dimensions of tourists' aesthetic judgment in the context of both nature-based and urban tourist destinations, and sound is identified as one of the nine themes. Nonetheless, generally speaking, studies on tourist satisfaction in a traditional way take no consideration of sound, or just treat sound as one of multiple factors that affect tourist satisfaction (Bazneshin, Hosseini, \& Azeri, 2015; Alegre \& Garau, 2010; Kirillova, Fu, Lehto, \& Cai, 2014) especially when examining tourist satisfaction from the perspective of the product and service quality domain.

Tourist satisfaction is rarely discussed from the perspective of sensescapes, largely due to the fact that the tradition of geography and tourism tends to place the central importance on 'the faculty of sight' (Saldanha, 2009, p. 236). As a result, understanding of the relationship between tourist satisfaction and soundscape perception, especially soundscape satisfaction, remains limited. Therefore, this paper aims to examine the popular theme of tourist satisfaction from the neglected perspective of the soundscape to examine the relationship between soundscape satisfaction and tourist satisfaction. The question this study seeks to answer is: what is the exact role of soundscape satisfaction in forming holistic tourist satisfaction from the perspective of sensory experiences? From the sensory experience perspective and for the purpose of this study, we propose that tourist satisfaction could be and should be considered as the integrative and comprehensive subjective assessment of tourists' sensory experiences, which are composed of landscape satisfaction through sight, soundscape satisfaction through sound, smellscape satisfaction through smell, tastescape satisfaction through taste and touchscape satisfaction through touch. Factors such as sound preference, soundscape expectation and soundscape perception are examined in this study in order to identify their respective influences on the relationship between soundscape satisfaction and tourist satisfaction. The role of soundscape satisfaction in mediating between influencing factors and tourist satisfaction is also discussed in this paper.

\section{SOUNDSCAPE SATISFACTION AND TOURIST SATISFACTION}

\subsection{Soundscape and Soundscape Satisfaction}

The soundscape, proposed by Canadian composer and ecologist Schafer in the 1970s, is a sound environment emphasizing the human awareness of their auditory perceptions or social and cultural understandings (Schafer, 1999). The International Organization of Standardisation (ISO, 2014, p. 12913-1), the soundscape is defined as the 'acoustic environment as perceived or experienced and/or understood by a person or people, in context'. In tourism, the soundscape refers to the acoustic environment perceived by tourists from their first step into the destination until their departure. Apart from the two important aspects already mentioned, sound would affect tourists' experience because it accompanies the whole process of tourists visiting, and cannot be avoided under most circumstances. In other words, whether tourists like the soundscape of a destination or not, they have no choice 
but to listen in a given place and space (Liu et al., 2013). Therefore, the source (human-made or nature-made), pace (lively or peaceful), volume (loud or quiet) and region (local or exotic) of sound would all have an influence on tourists' experience, and further affect their assessment of visiting satisfaction. Moreover, due to the different personalities of tourists, their preferences and expectations of the soundscape, as well as the time, place and their emotional mood at the very moment of listening to the sound, would also play a part in forming the whole perception of tourist satisfaction. In short, from the perspective of sensory experience, the soundscape is a significant element in tourists' judgment of the aesthetics of a destination in addition to visual stimuli (Kirillova et al., 2014).

There is no exact definition of soundscape satisfaction in the literature. According to the definition of satisfaction, satisfaction refers to the positive evaluation results of different experiences and perceptions, therefore soundscape satisfaction could be perceived as a positive perception and evaluation of the soundscape by people who are using or have been using the acoustic environment. In the field of acoustics, the relationship between landscape and soundscape satisfaction has been examined and the results show that there is a significant correlation between them (Kang, 2006, 2014). Other related studies are on soundscape evaluation, which includes evaluation of acoustic comfort (Yang \& Kang, 2005) and of the pleasantness and vibrancy of the soundscape (Hall, Irwin, Edmondson-Jones, Phillips, \& Poxon, 2013). It is noticeable that many studies on soundscape evaluation in acoustics are mainly conducted in urban public open spaces such as urban parks and the respondents are usually not tourist oriented. In tourism, studies on the soundscape are mainly conducted in national parks with the focus on the influences of noise pollution on tourists. Mace, Corser, Zitting and Denison (2013) argue that seeking the sounds of nature is the main purpose of visitors travelling to national parks, and whether their psychological needs are fulfilled or not depends on the relationship between soundscape experience and expectations. Based on this recognition, they conduct research to reveal the effects of aircrafts on the national park experience. Merchan, Diaz-Balteiro and Solino (2014) measured the influences of noise pollution on national park visitors from the perspective of economic valuation. Taff et al. (2014, p. 126) argue that exposure to sounds of aircraft in natural parks would depreciate visitors' experiences, but messaging visitors about the presence of overflying aircraft would improve the acceptability of aircraft sounds to visitors by as much as $15 \%$. Drawing on the previous findings about noisy soundscapes and tourist experiences, the following hypothesis is proposed:

H1: Soundscape satisfaction positively influences tourists' satisfaction.

\subsection{Sound Preference and Tourist Satisfaction}

Preference is the first factor that would affect the perception and assessment of a soundscape. Ge and Hokao (2005, p. 456) suggest 'sound preference is a critical issue in trying to reveal the perceptual nature of human beings'. Hall, Irwin, Edmondson-Jones, Phillips and Poxon (2013) also imply that the perception of a soundscape is a personal subjective experience that relates to personal preference, while Jennings and Cain $(2013$, p. 3$)$ state that 'the perception of a soundscape is inherently personal and affected by what a listener, each with a unique set of experiences and preferences, brings to the listening situation'. From an applied acoustics perspective, previous research findings show that age and education level significantly affect sound preference universally (Yu and Kang, 2010). However, attempt to standardize soundscape preference assessment, Brown, Kang and Gjestl and (2011, p. 388) argue that a person's preference of soundscape differ evidently in different 
places and contexts, and that the soundscape of a place would be preferred because it is peaceful, or lively, or 'creates a sense of excitement', or 'provides information' and so on. In tourism, Schwarz (2013, p. 383) explains the differences of tourists' sound preferences come from tourists' choices of 'the ideal sonic order of nature sites'. Therefore, 'sonic preferences shape general tourist preferences' and 'tourist experiences are also sonic experiences' (Schwarz, 2013, p. 399). Hence, it is hypothesized that:

H2a: Sound preference positively influences tourists' soundscape satisfaction. $\mathrm{H} 2 \mathrm{~b}$ : Sound preference positively influences tourists' satisfaction.

H2c: Sound preference positively influences tourists' soundscape perception.

\subsection{Soundscape Expectation and Tourist Satisfaction}

In the field of tourist satisfaction studies, expectation is a concept closely related to tourist experiences and satisfaction. Bosque \& Martin (2008, p. 554) define expectation as 'the individual's beliefs about how a product is likely to perform in the future'. The cognitive and affective model developed by Oliver (1993) refers expectations as standards for comparison while conducting cognitive evaluations of consumers' satisfaction. Bosque and Martin's (2008, p. 564) cognitive-affective model of tourist satisfaction and their case study results support the hypothesis that 'the higher the tourist expectations, the higher the satisfaction with the destination'. Other studies also show the direct relationship between expectations and consumer satisfaction (e.g. Bosque, Martı'n, \& Collado, 2006; Sheng\& Chen, 2012; Wong \& Dioko, 2013). In the acoustics research field, Bruce and Davies's study (2014) explores the relationship between soundscape expectation and soundscape perception, and found out that expectation affecting soundscape perception in several different ways. Based on the results of these previous studies, three hypotheses can be proposed:

H3a: The higher the soundscape expectation, the higher the soundscape satisfaction with the destination.

$\mathrm{H} 3 \mathrm{~b}$ : The higher the soundscape expectation, the higher the tourist satisfaction with the destination.

H3c: Soundscape expectation positively influences the soundscape perception of the destination.

\subsection{Soundscape Perception and Tourist Satisfaction}

Hong and Jeon (2015, p. 80) suggest 'there are two main factors of soundscape perception: one is related to the pleasantness or preference of sounds, and the other is associated with the eventfulness and variety of sounds representing the temporal structure of a soundscape'. The perceptual dimensions of soundscapes were explored using verbal descriptions such as 'pleasant', 'favorable' or 'harmonious' in their study. In addition, their study show that soundscape perception is closely related to various visual factors, among which "the aesthetic quality of the visual environment is considered to be the most significant factor' (Hong \& Jeon, 2015, p. 80). Liu, Kang, Behm and Luo (2014) explore the relationship between visual landscape and soundscape perception in city parks and conclude that local landscape spatial patterns could be more influential on soundscape perception than on-site landscape composition. 
Soundscape perception is the basis for soundscape evaluation. A series of soundscape evaluation studies in acoustics are carried out based on the data collected by questionnaires and deep interviews about correspondents' individual perception and understanding of the sound (Yang \& Kang, 2005; Ge \& Hokao, 2005; Szeremeta \& Zannin, 2009). The relationship between sonic properties and listeners' perception of sound quality has also been explored using different methods (Hall et al., 2013, p. 5). In tourism, visitors' emotional state are considered to be one of the main factors that affects tourist satisfaction (Brunner-Sperdin, Peters, \& Strobl, 2012), while the emotional experience gained by visitors is often expressed as a sensory perception of the soundscape (Votsi, Mazaris, Kallimanis, \& Pantis, 2014, p. 10). Based on these previous studies, three hypotheses can be proposed, as follows:

H4a: Soundscape perception positively influences tourists' soundscape satisfaction. H4b: Soundscape perception positively influences tourist satisfaction.

$\mathrm{H} 4 \mathrm{c}$ : Soundscape perception is positively influenced by sound preference.

\subsection{Conceptual Framework}

The conceptual framework is constructed as shown in Figure 1. It proposes that soundscape satisfaction positively influences tourist satisfaction $(\mathrm{H} 1)$; tourists' sound preference positively influences soundscape satisfaction $(\mathrm{H} 2 \mathrm{a})$, tourist satisfaction $(\mathrm{H} 2 \mathrm{~b})$ and soundscape expectation $(\mathrm{H} 2 \mathrm{c})$; the higher the soundscape expectation, the higher the soundscape satisfaction with the destination (H3a), and the higher the tourist satisfaction with the destination(H3b); soundscape expectation positively influences the soundscape perception of the destination $(\mathrm{H} 3 \mathrm{c})$. Soundscape perception positively influences tourists' soundscape satisfaction (H4a) and tourist satisfaction ( $\mathrm{H} 4 \mathrm{~b})$; and, last, soundscape perception is positively influenced by sound preference $(\mathrm{H} 4 \mathrm{c})$.

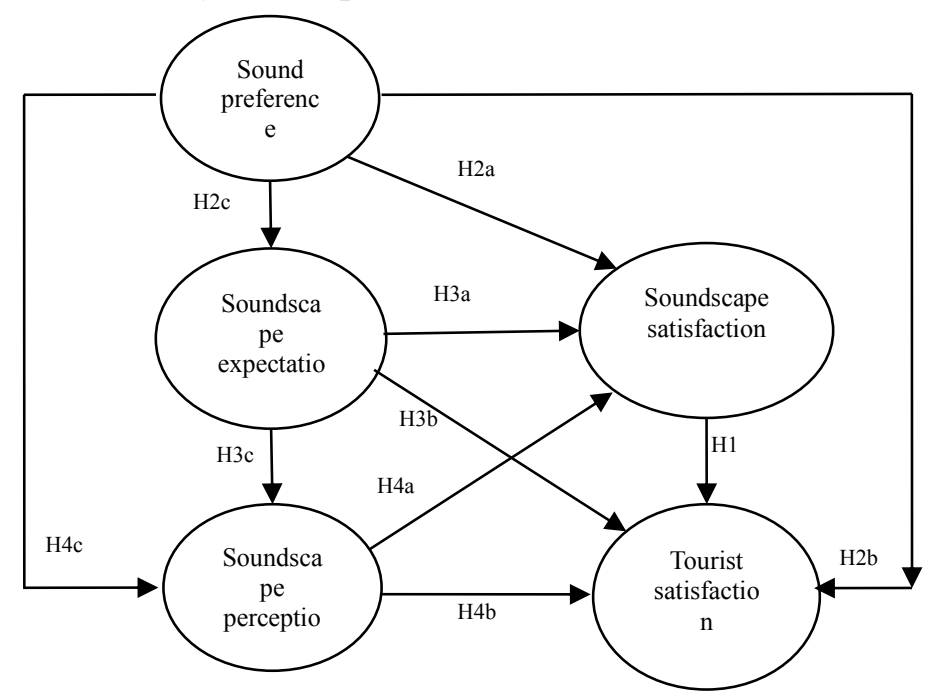

Figure1 Conceptual framework 


\section{METHOD}

\subsection{Questionnaire Design and Measurement}

The questionnaire used for this research is composed of three parts: part one demographic information on respondents, including gender, age, education level and occupation; part two -measurement of the five latent variables: sound preference, soundscape expectation, soundscape perception, soundscape satisfaction and tourist satisfaction; and part three -two open questions: (a) how important do you think the soundscape is for destinations? (b) what are the influences of the soundscape on your visiting experiences? Measurements of all the five latent variables in the second part are developed based on a comprehensive literature review on soundscape and tourist satisfaction. A 5-level Likert scale is used to measure respondents' choices. Respondents are asked to indicate their levels of agreement on each term on a 5-point scale ( $1=$ strongly disagree; $5=$ strongly agree $)$. Five tourism experts were consulted during the questionnaire development to ensure the face validity of the instrument. A pilot study with 30 respondents was also carried out before finalizing the questionnaire for actual data collection.

Different from other studies of sound preference in acoustics, sound preference in this study focuses on three aspects: purpose of sound preference, importance of sound preference and behavior representation of sound preference (Yu \& Kang, 2010; Xie, Li, \& Kang, 2014). Soundscape expectations are measured by three dimensions, including eagerness to hear the soundscape, and the comfort and the uniqueness of the soundscape, which are adapted from the study of Brown et al. (2011). Soundscape perception is measured by five aspects also based on Brown et al.'s study (2011) and Hong and Jeon's study (2015): the tranquility, the uniqueness, the natural nature, the impressiveness and the fondness of the soundscape.

Soundscape satisfaction is measured by three aspects: (1) The soundscape in Hongcun meets my expectations. (2) I am satisfied with the soundscape. (3) I am comfortable with the soundscape. These terms were designed on the basis of the scale of Yoon and Uysal (2005) and the study of Ren and Kang (2015). Following the scale of Bosque and Martin (2008) and Yoon and Uysal (2005), three terms were developed to measure tourist satisfaction: (1) I have really enjoyed it. (2) My choice is a wise one. (3) The tour experience meets my expectations.

\subsection{Data Collection and Sample}

Data were collected through a self-administered questionnaire in July 2015 in the ancient Chinese village of Hongcun. The village became a UNESCO world heritage site in 2000 and it is a popular tourist destination for cultural and heritage tourism, with an impressive landscape, and is well known for its unique soundscape. In order to randomize the sampling process, data were collected in three different locations in Hongcun during different times of the day in July 2015. A total of 420 survey questionnaires were distributed and 403 were returned, among which 357 valid responses were used for data analysis, representing an $85 \%$ response rate. 46 responses were disqualified due to extensive missing values.

\subsection{Data Analysis}

Frequency counts and percentages are used to summarize the respondents' demographic profile. Structural equation modeling is applied to the data using the software LISREAL 8.7. At the first stage, a confirmatory factor analysis (CFA) is conducted to validate the factor structure of the measurement model. At the second stage, the interrelationships between the five constructs proposed in the conceptual framework are tested. Meanwhile, the mediating 
effect of soundscape satisfaction is examined by proposing a new model.

\subsection{Results}

The demographic profile of the sample is shown in Table 1. The sample consists of $51 \%$ males and $49 \%$ females. More than $61 \%$ are between 18 and 24 years old; $14.8 \%$ of the respondents are in the age bracket between 25 and 34 years; $12.1 \%$ are between 35 and 44 years old. In terms of occupation group, most of the visitors are students (62.8\%), while more than $10 \%$ of them are employees, and $7.8 \%$ are teaching staff. Among the respondents more than $80 \%$ have an education level of undergraduate or graduate.

Table 1 Demographic profile

\begin{tabular}{lll}
\hline Demographic profile & Frequency counts & Percentage (\%) \\
\hline Gender & & \\
Male & 182 & 51 \\
Female & 175 & 49 \\
Age & & \\
& & \\
$<18$ & 22 & 6.2 \\
$18-24$ & 220 & 61.6 \\
$25-34$ & 53 & 14.8 \\
$35-44$ & 43 & 12.1 \\
$>44$ & 19 & 5.3 \\
Occupation & & \\
& & \\
Government staff & 6 & 1.7 \\
Company employee & 38 & 10.6 \\
Businessman & 10 & 2.8 \\
Teacher & 28 & 7.8 \\
Student & 224 & 62.8 \\
Freelance & 16 & 4.5 \\
Retiree & 5 & 1.4 \\
Other & 30 & 8.4 \\
Education & & \\
& & \\
Middle school or below & 15 & 4.2 \\
High school & 45 & 12.6 \\
Undergraduate & 276 & 77.3 \\
Graduate & 21 & 5.9 \\
\hline
\end{tabular}

\subsection{Measurement Model}

The overall measurement quality is tested using the method of CFA with all the variables of the model. As presented in Table 2, all five latent variables (sound preference, soundscape expectation, soundscape perception, soundscape satisfaction and tourist satisfaction) are included in the measurement model and each of them is measured by three or five observed variables (Table 2). The goodness of fit statistics are as follows: $\chi^{2}(109)=306.151(p<0.0)$, Root Mean Square Error of Approximation (RMSEA) $=0.071$, Goodness of Fit Index $(\mathrm{GFI})=0.911$, Normed Fit Index $(\mathrm{NFI})=0.921$, Comparative Fit Index $(\mathrm{CFI})=0.947$, NonNormed Fit Index $(\mathrm{NNFI})=0.98$, which shows that the model is fit for the data. In addition, the reliability, convergent validity and discriminant validity of the model are confirmed. 
Table 2 The result of CFA

\begin{tabular}{|c|c|c|c|c|c|}
\hline $\begin{array}{c}\text { Latent } \\
\text { variable }\end{array}$ & Construct and items & $\begin{array}{c}\text { Standardiz } \\
\text { ed } \\
\text { loading }\end{array}$ & SMC & C.R. & AVE \\
\hline \multirow{3}{*}{$\begin{array}{l}\text { SPF } \\
\text { (sound } \\
\text { preference) }\end{array}$} & \multirow{2}{*}{$\begin{array}{l}\text { (SPF1) I prefer to listen to the soundscape of Hongcun. } \\
\text { (SPF2) The soundscape of Hongcun is of great } \\
\text { significance to me. }\end{array}$} & 0.65 & 0.423 & 0.740 & 0.488 \\
\hline & & 0.67 & 0.449 & & \\
\hline & $\begin{array}{l}\text { (SPF3) I am active in looking for soundscapes in } \\
\text { Hongcun. }\end{array}$ & 0.77 & 0.593 & & \\
\hline \multirow{3}{*}{$\begin{array}{l}\text { SEP } \\
\text { (soundscape } \\
\text { expectation) }\end{array}$} & \multirow{2}{*}{$\begin{array}{l}\text { (SEP1) I desired to listen to the sound in Hongcun. } \\
\text { (SEP2) I expect that the sound in Hongcun is } \\
\text { comfortable. }\end{array}$} & 0.76 & 0.578 & 0.811 & 0.588 \\
\hline & & 0.76 & 0.578 & & \\
\hline & (SEP3) I expect that the sound in Hongcun is unique. & 0.78 & 0.608 & & \\
\hline & (SPP1) The soundscape in Hongcun is tranquil. & 0.70 & 0.490 & 0.880 & 0.597 \\
\hline SPP & (SPP2) The soundscape in Hongcun is unique. & 0.76 & 0.578 & & \\
\hline (soundscape & (SPP3) The soundscape in Hongcun is original. & 0.74 & 0.548 & & \\
\hline \multirow[t]{2}{*}{ perception) } & (SPP4) The soundscape in Hongcun is impressive. & 0.76 & 0.578 & & \\
\hline & (SPP5) I enjoyed the soundscape in Hongcun. & 0.89 & 0.792 & & \\
\hline SS & (SS1) The soundscape meets my expectations & 0.80 & 0.640 & 0.896 & 0.742 \\
\hline (soundscape & (SS2) I am comfortable with the soundscape. & 0.87 & 0.757 & & \\
\hline satisfaction) & (SS3) I am satisfied with the soundscape. & 0.91 & 0.828 & & \\
\hline TS & (TS1) I have really enjoyed the tour in Hongcun. & 0.84 & 0.706 & 0.866 & 0.684 \\
\hline (tourist & (TS2) I have made a wise decision to visit Hongcun. & 0.83 & 0.689 & & \\
\hline satisfaction) & (TS3) The whole experience meets my expectations & 0.81 & 0.656 & & \\
\hline
\end{tabular}

$* * *$ Significant at the 0.001 level; $\mathrm{AVE}=$ average variance extracted

\subsection{Structural Model}

All the hypotheses are estimated using maximum likelihood estimation. The goodness of fit statistics are displayed: $\chi^{2}(109)=306.151(\mathrm{p}<0.0), \chi^{2} / \mathrm{df}=2.809$, RMSEA $=0.071$, $\mathrm{GFI}=0.911, \mathrm{NFI}=0.921, \mathrm{CFI}=0.947, \mathrm{NNFI}=0.98, \mathrm{RMR}=0.047, \mathrm{IFI}=0.948, \mathrm{RFI}=0.902$. According to the cut-off criteria, this model is fit for the data. The results show that hypotheses 1, 2c, 2d, 3b and 4a are supported, while hypotheses $2 \mathrm{a}, 2 \mathrm{~b}, 3 \mathrm{a}, 3 \mathrm{c}$ and $4 \mathrm{~d}$ are rejected, as shown in Figure 2.

Soundscape satisfaction has a positive and significant effect on tourist satisfaction $(\mathrm{t}=4.747, \mathrm{p}<.01)$, supporting H1. Results also demonstrate that sound preference significantly influences soundscape expectation $(t=10.171, p<.01)$ and soundscape perception $(t=3.286$, $\mathrm{p}<.01$ ), which support $\mathrm{H} 2 \mathrm{c}$ and $\mathrm{H} 2 \mathrm{~d}$. However, sound preference does not appear to influence soundscape satisfaction $(\mathrm{H} 2 \mathrm{a})$ or tourist satisfaction $(\mathrm{H} 2 \mathrm{~b})$.

The relationship between soundscape expectation and tourist satisfaction $(\mathrm{H} 3 \mathrm{~b})$ is proved to be supported $(\mathrm{t}=2.808, \mathrm{p}<.01)$. Nevertheless, results do not indicate that soundscape expectation directly influences soundscape satisfaction (H3a) or soundscape perception (H3c). On the other hand, soundscape perception has a direct effect on soundscape satisfaction (H4a, $\mathrm{t}=13.296, \mathrm{p}<.01$ ). However, there is no relationship between soundscape perception and tourist satisfaction $(\mathrm{H} 4 \mathrm{~b})$. 


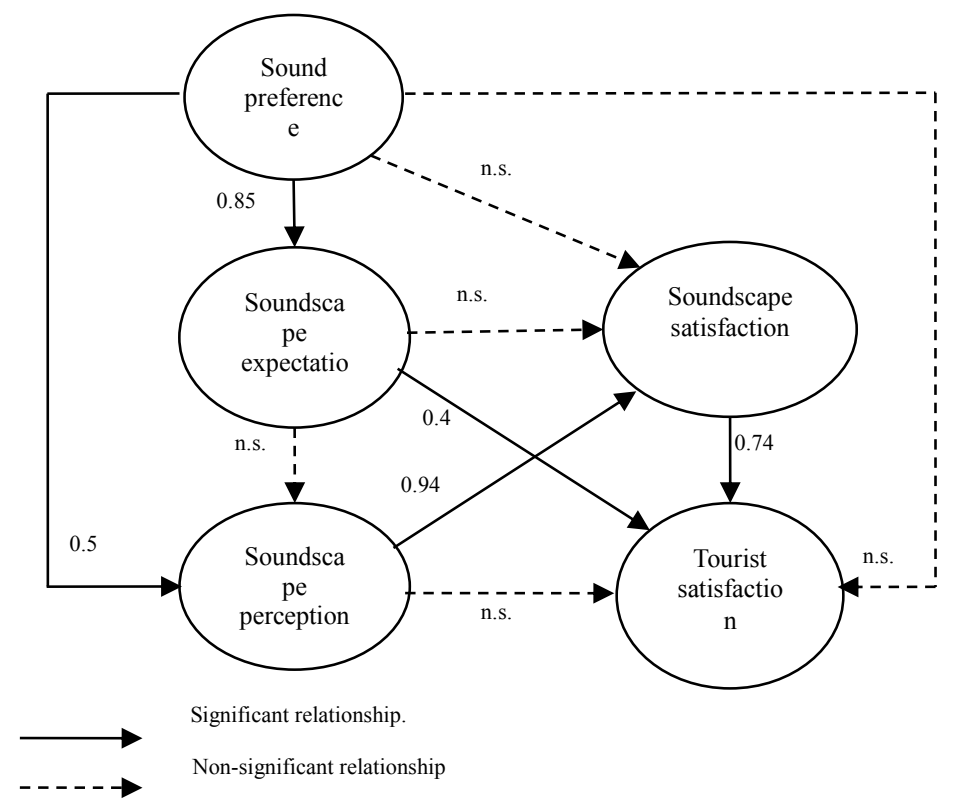

Figure2 Estimates of overall model

\subsection{Mediating Effects of Soundscape Satisfaction}

According to Baron and Kenny's (1986) classic causal steps approach, to test the mediating effects of soundscape satisfaction four conditions must be met: first, there is a significant direct effect of the predictor (sound preference, soundscape expectation and soundscape perception) on the outcome variable (tourist satisfaction); second, there is a direct link between the predictor and the mediator (soundscape satisfaction); third, the mediator must be significantly related to the outcome variable, when there is a link between the predictor and the outcome variable; fourth, the relationship between the predictor and the outcome variable must be significantly reduced when the mediator enters the model. In the fourth step, if the relationship between the predictor and the outcome variable is not significant, complete mediation is established. Otherwise, partial mediation is supported.

In order to further understand the effects, if any, that sound could have on tourist satisfaction, a model that excludes soundscape satisfaction (see Figure 3) is also developed to test the relationship between sound preference, soundscape expectation, soundscape perception and tourist satisfaction. The results show that soundscape expectation and soundscape perception have a significant effect on tourist satisfaction, while no direct link between sound preference and tourist satisfaction was found. The significant relationship between soundscape perception and tourist satisfaction is also confirmed. However, Figure 3 does not show the direct effect of soundscape expectation on soundscape perception. Thirdly, soundscape satisfaction is significantly related to tourist satisfaction in Figure2. In step 4, Figure 2 demonstrates the complete mediation of soundscape satisfaction between soundscape perception and tourist satisfaction, since the path between soundscape perception and tourist satisfaction becomes insignificant when soundscape satisfaction is included.

The fit indices of the new model are as follows: $\chi^{2}(71)=194.475(\mathrm{p}<0.0), \chi^{2} / \mathrm{df}=2.739$, RMSEA $=0.070, \mathrm{GFI}=0.929, \mathrm{NFI}=0.928, \mathrm{CFI}=0.953, \mathrm{NNFI}=0.953, \mathrm{RMR}=0.047, \mathrm{IFI}=0.953$, $\mathrm{RFI}=0.908$. Therefore, the new proposed model has a good fit. 


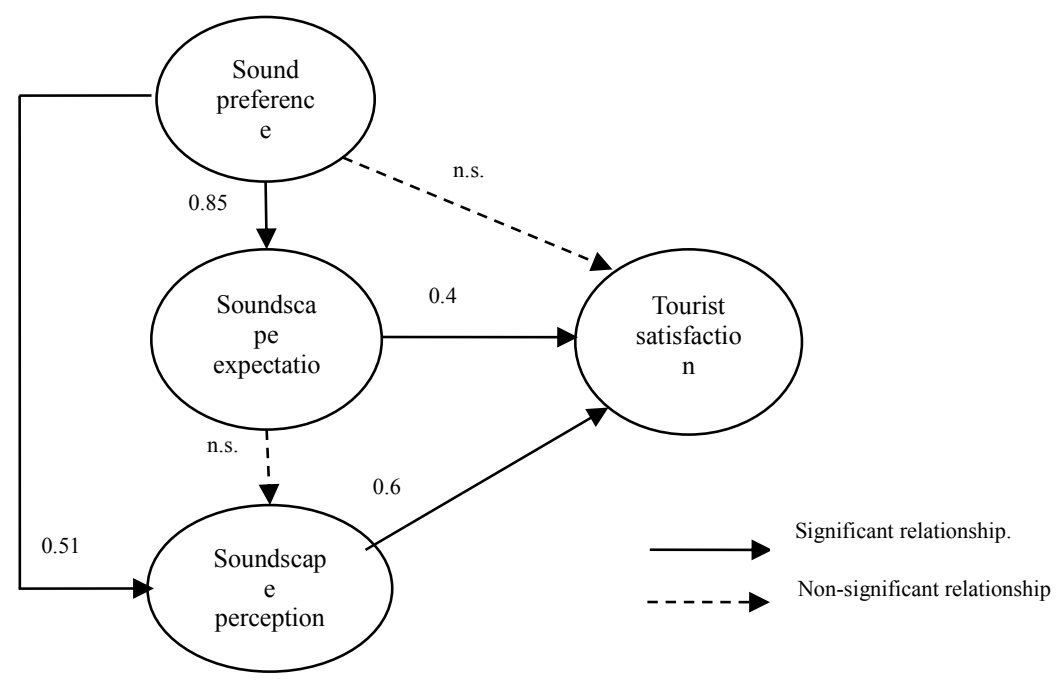

Figure3 New model without soundscape satisfaction

\section{CONCLUSION}

The sensory dimensions of tourist experiences have been proposed as the new direction of tourist experience study (Agapito et al., 2014). This paper contributes to this emerging field of tourism research by validating the relationship between the soundscape and its effects on tourist satisfaction. As the positive subjective evaluation result of tourist experiences, tourist satisfaction could also be examined from the perspective of sensory experiences. Previous studies have confirmed that a noisy soundscape has an influence on tourist experiences (Mace et al., 2013), yet there remains considerable ambiguity about the relationship between soundscape and tourist satisfaction. Tourist satisfaction studies traditionally consider sound as well as the soundscape as one of the environmental factors that affect tourist experiences. However, this paper argues that following the recent development of sensory experience research, tourist satisfaction studies should be conducted from a new tourist sensory experience perspective in order to assess tourists' sensory engagement and how each aspect of the sensory experience, in this case the soundscape, affects overall tourist satisfaction. A number of significant findings are highlighted below together with their implications for tourism research as well as for tourism and destination marketing practice.

First, this paper confirms that tourist experiences are not only visual but also multisensory (Jensen et al., 2015). It suggests that different from traditional tourist satisfaction studies, which mainly focus on the perceived quality of products and services, tourist sensory experience should be included and assessed as a key factor that affects tourist satisfaction. The results of this research reaffirm the view of Isacsson, Alakoski and Bäck (2009, p. 167) that multiple senses including sound, smell, touch, taste and sight need to be activated in order to 'enhance the feeling of authenticity and experience. The effect of soundscape could have on tourist experience and subsequently tourist satisfaction thus need to be more comprehensively assessed to aid tourism experiential product development as well as destination marketing activities.

Second, this paper offers empirical evidence to better understand tourist sensory satisfaction by validating the relationship between soundscape satisfaction and tourist 
satisfaction. It makes a progressive contribution to the tourist satisfaction literature by identifying the role of soundscape satisfaction in forming total tourist sensory satisfaction. The results of this study suggest that soundscape satisfaction positively influences tourist satisfaction, which implies that in order to enhance tourist satisfaction, the soundscape needs to be well designed and managed to complement the landscape and other sensory aspects of the tourism experience. In the absence of a working definition, we have made the first attempt to define tourist sensory satisfaction as 'the integrative and comprehensive subjective assessment of tourists' sensory experiences, which are mainly composed of landscape satisfaction by sight, soundscape satisfaction by hearing, smellscape satisfaction by smell, tastescape satisfaction by taste and touchscape satisfaction by touch'.

Third, this paper reveals that factors such as sound preference, soundscape expectation and soundscape perception have different influences on soundscape satisfaction and tourist satisfaction. The findings show that there is no obvious correlation among sound preference, soundscape satisfaction and tourist satisfaction, which differs from traditional tourist satisfaction studies such as food preference (Chang, Kivela, \&Mak, 2010). The reason deduced from open questions with respondents maybe that although most of the tourists recognize the importance of the soundscape to their experiences, sound and the soundscape are seldom taken into consideration when choosing a destination. The findings of this study also expose the complex relationship between expectation and satisfaction; that is, there is no significant correlation between soundscape expectation and soundscape satisfaction. However, there is a significant correlation between soundscape expectation and tourist satisfaction. The contradiction confirms that expectation is a factor affecting tourist satisfaction on the one hand, and shows that soundscape satisfaction has not been an important element for evaluating tourists' experiences on the other. This maybe because Chinese tourists who are generally engaged with mass tourism activities are used to the relatively crowded and noisy acoustic environment of destinations.

Furthermore, it also seems contradictory that there is a significant correlation between soundscape perception and soundscape satisfaction, while there is no significant correlation between soundscape perception and tourist satisfaction. However, such a state of contradiction once again suggests that the respondents, Chinese domestic tourists, might only have noticed the importance of the soundscape when they were asked to evaluate the perceived quality of the soundscape, and they did not take the soundscape perception factor seriously when evaluating their overall tourist satisfaction. In other words, despite the fact that the case, Hongcun village, is renowned for its beautiful architectural landscape and the combination of the visual landscape of folk houses, lakes, trees and rivers masks the role of the soundscape, tourists in China may still pay far more attention to the visual landscape than to other sensescapes such as the soundscape.

Finally, the mediating role of soundscape satisfaction was measured by a new model, eliminating the latent variable of soundscape satisfaction, and the results revealed that soundscape satisfaction has no effective mediating role in the relationship between tourist satisfaction and sound preference as well as soundscape expectation; however, soundscape satisfaction has a negative influence on the relationship between soundscape perception and tourist satisfaction, which also confirms that tourists in China pay little attention to the perceived quality of the soundscape when assessing the quality of their travelling experiences. Such a result is in line with the common characteristics of Chinese tourists, for whom the main purpose of travelling is a demand for sightseeing. However, the importance of the soundscape, as well as the role of soundscape satisfaction in facilitating and enhancing 
tourist satisfaction, will become more important as tourists grow more demanding as mature tourists.

As with all studies, this research has a number of limitations. To start with, the research concentrates on the relationship between soundscape satisfaction and tourist satisfaction, and does not take into consideration other sensory experiences such as sight, taste, smell, touch and so on. Future studies may expand on this current research by developing multidimensional measures for evaluation of the tourist sensory experience that could potentially aid in the improvement of tourist satisfaction. Also, this study was conducted at a single UNESCO heritage site in China, so the study results may not be generalizable to other types of destinations. A comparison study of soundscape influence on tourist satisfaction that includes multiple destinations in different cultural settings will be useful to investigate how the soundscape could be better measured and managed to enhance tourist satisfaction. Lastly, the respondents of this study are mainly Chinese domestic tourists, and their soundscape perception and expectations may be different from those of international tourists. Future research with a larger sample size that includes international tourist participants could lead to a better understanding of the possible links between tourist experience, culture and tourist sensory satisfaction.

\section{References}

Agapito, D., Mendes, J., \& Valle, P. (2013). Exploring the conceptualization of the sensory dimension of tourist experiences. Journal of Destination Marketing \& Management, 2: 62-73.

Agapito, D., Valle, P., \& Mendes, J. (2014). The sensory dimension of tourist experiences: Capturing meaningful sensory-informed themes in Southwest Portugal. Tourism Management, 42: 224-237.

Alegre, J., \& Garau, J. (2010). Tourist satisfaction and dissatisfaction. Annals of Tourism Research, 37(1): 52-73.

Baron, R.M., \& Kenny, D.A. (1986). The moderator-mediator variable distinction in social psychological research: Conceptual, strategic and statistical considerations. Journal of Personality and Social Psychology, 51: 1173-1182.

Bazneshin, S.D., Hosseini, S.B., \& Azeri, A.R.K. (2015). The physical variables of tourist areas to increase the tourists' satisfaction regarding the sustainable tourism criteria: Case study of Rudsar Villages, Sefidab in Rahim Abad. Procedia-Social and Behavioral Sciences, 201: 128-135.

Benfield, J.A., Bell, P.A., Troup, L.J., \& Soderstrom, N.C. (2010). Aesthetic and affective effects of vocal and traffic noise on natural landscape assessment. Journal of Environmental Psychology, 30(1): 103-111.

Bosque, I.R., Martı'n, H.S., \&Collado, J. (2006). The role of expectations in the consumer satisfaction formation process: Empirical evidence in the travel agency sector. Tourism Management, 27: 410-419.

Bosque, I.R., \& Martin, H.S. (2008). Tourist satisfaction: A cognitive-affective model. Annals of Tourism Research, 35(2):551-573.

Briassoulis, H. (2002). Sustainable tourism and the question of the commons. Annals of Tourism Research, 29(4), 1065-1085. 
Brown, A.L., Kang, J., \&Gjestland, T. (2011). Towards standardization in soundscape preference assessment. Applied Acoustics, 72(6): 387-392.

Bruce, N.S., \& Davies, W.J. (2014). The effects of expectation on the perception of soundscapes. Applied Acoustics, 85: 1-11.

Brunner-Sperdin, A., Peters, M., \&Strobl, A. (2012). It is all about the emotional state: Managing tourists' experiences. International Journal of Hospitality Management, 31: 23-30.

Chang, R.C.Y., Kivela, J., \&Mak, A.H.N. (2010). Food preferences of Chinese tourists. Annals of Tourism Research, 37(4): 989-1011.

Chen, C., \& Chen, F. (2010). Experience quality, perceived value, satisfaction and behavioral intentions for heritage tourists. Tourism Management, 31(1): 29-35.

Daugstad, K. (2008). Negotiating landscape in rural tourism. Annals of Tourism Research, 35(2): 402-426.

Edensor, T. (2000). Staging tourism: Tourists as performers. Annals of Tourism Research, 27(2): 322-344.

Ge, J., \&Hokao, K. (2005). Applying the methods of image evaluation and spatial analysis to study the sound environment of urban street areas. Journal of Environmental Psychology, 25: 455-466.

Hall, D.A., Irwin, A., Edmondson-Jones, M., Phillips, S., \&Poxon, J.E.W. (2013). An exploratory evaluation of perceptual, psychoacoustic and acoustical properties of urban soundscapes. Applied Acoustics, 74(2): 248-254.

Hong, J.Y., \& Jeon, J.Y. (2015). Influence of urban contexts on soundscape perceptions: A structural equation modeling approach. Landscape and urban planning, 141: 78-87.

Isacsson, A., Alakoski, L. \& Bäck, A. (2009). Using Multiple Senses in Tourism Marketing: The Helsinki Expert, Eckero Line and Linnanmaki Amusement Park Cases. TOURISMOS: An International Multidisciplinary Journal of Tourism, 4(3): 167-184.

ISO/DIS 12913-1 (2014). Acoustics. Soundscape Part 1: Definition and Conceptual Framework. Geneva: International Organization for Standardization.

Jennings, P., \& Cain, R. (2013). A framework for improving urban soundscapes. Applied Acoustics, 74(2): 293-299.

Jensen, M., Scarles, C. \& Cohen, S. A. (2015). A multisensory phenomenology of inter rail mobilities. Annuals of Tourism Research, 53: 61-76.

Kang, J. (2006). Urban Sound Environment. London: Taylor \& Francis Incorporating Spon.

Kang, J. (2014). Soundscape: Current progress and future development. New Architecture, (5): 4-7. (in Chinese).

Kang, M., \&Gretzel, U. (2011). Effects of podcast tours on tourist experiences in a national park. Tourism Management, 33(2): 440-455.

Kirillova, K., Fu, X., Lehto, X., \& Cai, L. (2014). What makes a destination beautiful? Dimensions of tourist aesthetic judgment. Tourism Management, 42: 282-293.

LaTour, S.A., \& Peat, N.C. (1979).Conceptual and Methodological Issues in Consumer Satisfaction Research, in W.L. Wilkie (Eds.), Advances in Consumer Research (431-440). Ann Arbor: Association for Consumer Research.

Liu A., Hu Z., Liu M., Deng, Z., \& Yao, C. (2013). Soundscape and its application in research of tourism geography: a new perspective. Geographical Research, 32(6): 1132-1142. (in Chinese).

Liu, J., Kang, J., Behm, H., \& Luo, T. (2014). Effects of landscape on soundscape perception: Soundwalks in city parks. Landscape and urban planning, 123: 30-40.

Lu, L., Chi, C.G., \& Liu, Y. (2015). Authenticity, involvement, and image: Evaluating tourist experiences at historic districts. Tourism Management, 50: 85-96.

Mace, B.L., Corser, G.C., Zitting, L., \& Denison, J. (2013). Effects of overflights on the 
national park experience. Journal of Environmental Psychology, (35): 30-39.

Merchan, C.I., Diaz-Balteiro, L., \& Solino, M. (2014). Noise pollution in national parks: Soundscape and economic valuation. Landscape and Urban Planning, 123(1): 1-9.

Morillas, J., Escobar, V., \& Gozalo, G. (2013). Noise source analyses in the acoustical environment of the medieval centre of Cáceres (Spain). Applied Acoustics, 2013, 74(4): 526-534.

Neal, J., \& Gursoy, D. (2008). A multifaceted analysis of tourism satisfaction. Journal of Travel Research, 47(1): 53-62.

Oliver, R. (1987). An Investigation of the Interrelationship between Consumer (Dis)satisfaction and Complaint Reports. Advances in Consumer Research, 14:218-222.

Oliver, R. (1993).Cognitive, affective, and attribute bases of the satisfaction response. Journal of Consumer Research, 20: 418-430.

Pan, S. \& Ryan, C. (2009). Tourism sense-making: the role of the senses and travel journalism. Journal of Travel and Tourism Marketing, 26 (7): 625-639.

Pheasant, R.J., Fisher, M.N., Watts, G.R., Whitaker, D.J., \& Horoshenkov, K.V. (2010). The importance of auditory-visual interaction in the construction of 'tranquil space'. Journal of Environmental Psychology, 30(4): 501-509.

Pizam, A., Neumann, Y., \& Reichel, A. (1978). Dimensions of tourist satisfaction with a destination area. Annals of Tourism Research, 5(3): 314-322.

Porteous, J. (1990). Landscapes of the Mind: Worlds of Sense and Metaphor. Toronto: University of Toronto Press.

Quan, S., \& Wang, N. (2004). Towards a structural model of the tourist experience: An illustration from food experiences in tourism. Tourism Management, 25: 297-305.

Rantala, O., \& Valtonen, A. (2014). A rhythm analysis of touristic sleep in nature. Annals of Tourism Research, 47: 18-30.

Richards, V., Pritchard, A., \& Morgan, N. (2010). (Re)Envisioning tourism and visual impairment. Annals of Tourism Research, 37(4): 1097-1116.

Ren, X., \& Kang, J. (2015). Effects of the visual landscape factors of an ecological waterscapeon acoustic comfort. Applied Acoustics, 96:171-179.

Rojeck, C., \& Urry, J. (1997). Touring cultures: transformations of travel and theory. London: Routledge.

Saldanha, A. (2009). Soundscape. In: R. Kitchin \& N.Thrift (Eds.), International Encyclopedia of Human Geography (pp. 236-240). Oxford: Elsevier Ltd.

Schafer, R. M. (1999). The soundscape: our sonic environment and the tuning of the world. Vermont: Inner Traditions Bear and Company.

Schwarz, O. (2013). What should nature sound like? Techniques of engagement with nature sites and sonic preferences of Israeli visitors. Annals of Tourism Research, 42: 382-401.

Sellars, A. (1998). The influence of dance music on the UK youth tourism market. Tourism Management, 19(6): 611-615.

Sheng, C., \& Chen, M. (2012). A study of experience expectations of museum visitors. Tourism Management, 33: 53-60.

Swan, J. E., \& Combs, L. J. (1976). Product performance and consumer satisfaction: A new concept. Journal of Marketing, 40: 25-33

Szeremeta, B., Zannin, P.H.T. (2009). Analysis and evaluation of soundscapes in public parks through interviews and measurement of noise. Science of the Total Environment, 407: 6143-6349.

Taff, D., Newman, P., Lawson, S.R., Bright, A., Martin, L., Gibson, A., \& Archie, T. (2014). The role of messaging on acceptability of military aircraft sounds in Sequoia National Park. Applied Acoustics, 84(1): 122-128.

Tarrant, M., Haas, G., \& Manfredo, M. (1995). Factors affecting visitor evaluations of aircraft 
overflights of wilderness. Society and Natural Resources, 8(4): 351-360.

Tse, D. K., \& Wilton, P. C. (1988). Models of consumer satisfaction: An extension. Journal of Marketing Research, 25, 204-212.

Urry, J. (2002). The tourist gaze: Leisure and travel in contemporary societies (2nd ed.). London: Sage.

Waitt, G., \& Duffy, M. (2010). Listening and tourism studies. Annals of Tourism Research, $37(2), 457-477$.

Waltonen, A., \& Veijola, S. (2011). Sleep in tourism. Annals of Tourism Research, 38(1): 175192.

Watts, G.R., \&Pheasant, R.J. (2015). Tranquillity in the Scottish Highlands and Dartmoor National Park: The importance of soundscapes and emotional factors. Applied Acoustics, 89: 297-305.

Wolf, I.D., Stricker, H.K., \& Hagenloh, G. (2013). Interpretive media that attract park visitors and enhance their experiences: A comparison of modern and traditional tools using GPS tracking and GIS technology. Tourism Management Perspectives, 7: 59-72.

Wong, I.A., \&Dioko, L.A.N. (2013). Understanding the mediated moderating role of customer expectations in the customer satisfaction model: The case of casinos. Tourism Management, 36: 188-199.

Xie, H., Li, H., \& Kang, J. (2014). The urban soundscapes of Historic Conservation Areas in mountainous cities: A case study in Ciqikou, Chongqing. New Architecture, (5): 52-54. (in Chinese).

Yang, W., \& Kang, J. (2005). Acoustic comfort evaluation in urban open public spaces. Applied Acoustics, 66: 211-229.

Yoon, Y., \&Uysal, M. (2005). An examination of the effects of motivation and satisfaction on destination loyalty: a structural model. TourismManagement, 26(1):45-56.

Yu, L., \& Kang, J. (2010). Factors influencing the sound preference in urban open spaces. Applied Acoustics, 71: 622-633.

Votsi,N.P., Mazaris, A.D., Kallimanis, A.S., \& Pantis, J.D. (2014). Natural quiet: An additional feature reflecting green tourism development in conservation areas of Greece. Tourism Management Perspectives, 11: 10-17. 